\title{
Fabrication of Non-enzymatic Ni-Au Alloy Nanowire Glucose Sensor
}

\author{
Yi-Shu Hsieh, ${ }^{1}$ Po-Wen Wang, ${ }^{1}$ Chien-Yu Li, ${ }^{1}$ Shang-Ju Hsieh, ${ }^{1}$ \\ Ching-Yu Wang, ${ }^{1}$ Dei-Wei Chou, ${ }^{2}$ Na-Fu Wang, ${ }^{3}$ and Mau-Phon Houng ${ }^{*}$ \\ ${ }^{1}$ Department of Electrical Engineering, Institute of Microelectronics, \\ National Cheng Kung University, No. 1, University Rd, Tainan 701, Taiwan \\ ${ }^{2}$ Department of Military Meteorology, Air Force Institute of Technology, Kaohsiung 820, Taiwan \\ ${ }^{3}$ Department of Electronic Engineering, Center for Environmental Toxin and Emerging-Contaminant Research, \\ Super Micro Mass Research \& Technology Center, Cheng Shiu University, \\ No. 840, Chengcing Rd, Niaosong Dist., Kaohsiung City 83347, Taiwan
}

(Received April 24, 2019; accepted April 22, 2020)

Keywords: non-enzymatic, glucose sensor, $\mathrm{Ni}-\mathrm{Au}$ alloy nanowire, anodic aluminum oxide (AAO)

We fabricated a non-enzymatic $\mathrm{Ni}-\mathrm{Au}$ alloy nanowire electrochemical glucose sensor on a p-silicon-based anodic aluminum oxide (AAO) template. The advantages of the Ni-Au glucose sensor are its high sensitivity and stability, and fast reaction. In contrast to a traditional enzymatic glucose sensor, the non-enzymatic glucose sensor is reusable, enabling its long-term use by patients with diabetes. Although the reduction voltages of $\mathrm{Ni}$ and $\mathrm{Au}$ are considerably different, the $\mathrm{Ni}-\mathrm{Au}$ alloy nanowires used in the sensor were fabricated successfully via the adjustment of the electrodeposition parameters. The $\mathrm{Ni}-\mathrm{Au}$ alloy nanowires exhibited a high crystallinity and a uniform arrangement with an average height of $750 \mathrm{~nm}$. The $\mathrm{Ni}-\mathrm{Au}$ alloy glucose sensor exhibited a linear range of $0-3 \mathrm{mM}$, a sensitivity of $1893 \mu \mathrm{A} / \mathrm{mMcm}^{2}$, and a detection limit of $1 \mu \mathrm{M}$. Superior selectivity and stability over at least 30 days were also observed. The characteristics show that $\mathrm{Ni}-\mathrm{Au}$ alloy nanowires have excellent glucose-sensing performance compared with single noble metal nanowires. The silicon-based AAO template also serves as a strong mechanical support of the $\mathrm{Ni}-\mathrm{Au}$ nanowires used for sensing. To our knowledge, our fabricated sensor is the first non-enzymatic glucose sensor to use $\mathrm{Ni}-\mathrm{Au}$ alloy nanowires.

\section{Introduction}

An increasing number of people suffer from diabetes. Therefore, rapid and precise glucose sensors are becoming increasingly important. Commercial glucose sensors including spectrophotometric, ${ }^{(1-3)}$ glucose, and electrochemical glucose sensors have been widely studied. An electrochemical glucose sensor exhibits the advantages of high sensitivity and stability, and a fast reaction. Electrochemical glucose sensors can be divided into enzymatic ${ }^{(4,5)}$ and nonenzymatic glucose sensors. ${ }^{(6,7)}$ Although enzymatic glucose sensors have a high sensitivity and a large measurement range, they are easily affected by $\mathrm{pH}$, temperature, and humidity. ${ }^{(8,9)}$ The

*Corresponding author: e-mail: mphoung@mail.ncku.edu.tw

https://doi.org/10.18494/SAM.2020.2479 
most serious problem is that their lifetime is too short for long-term use by diabetes patients. We have therefore focused on the fabrication of a non-enzymatic glucose sensor.

Owing to their advantages, many remarkable non-enzymatic glucose sensors with different structures and materials have been fabricated. ${ }^{(8-20)}$ Among these sensors, those using nanostructures have the highest redox ability. Noble metal electrodes including $\mathrm{Au}^{(10)}$ and $\mathrm{Pt}$ have also been used in glucose sensing. However, they have a low sensitivity and a high cost. Multilayer $^{(9,11,12)}$ and alloy structures ${ }^{(13-15)}$ have been used to solve the problems of noble metal electrodes because of their synergistic effect. Some studies ${ }^{(9)}$ have indicated that multilayer and alloy electrodes have better sensing characteristics because of their superior redox ability to a single-material electrode. Furthermore, the alloy structure can decrease the use of noble metals and reduce the total cost.

In this study, a $\mathrm{Ni}-\mathrm{Au}$ alloy nanowire was successfully fabricated using laboratorymade anodic aluminum oxide (AAO) grown on a p-type heavily doped silicon substrate by three-electrode pulse electrodeposition. Then, the oxidation peak and the sensitivity of the sensing electrode were investigated in $0.1 \mathrm{M} \mathrm{NaOH}$ by cyclic voltammetry $(\mathrm{CV})$ and observing the amperometric response.

\section{Materials and Methods}

\subsection{Reagents and instruments}

Acetone, methanol, oxalic acid, and dimethyl sulfoxide (DMSO) were obtained from JT Baker. Phosphate, glucose, amino acid (AA), and urea were purchased from Sigma-Aldrich. Boric acid and sodium hydroxide were purchased from Merck. Nickel chloride hexahydrate and tetrachloroauric acid tetrahydrate were obtained from Alfa Aesar. Uric acid (UA) was purchased from Acros Organics.

\subsection{Deposition of aluminum and fabrication of AAO template}

A p-type heavily doped silicon substrate was cleaned with hydrofluoric acid, acetone, methanol, and deionized water. First, the p-type heavily doped silicon substrate was soaked in hydrofluoric acid for $1 \mathrm{~min}$. Then, it was washed and dried with deionized water and an air gun, respectively. Next, it was cleaned again for 5 min each with acetone, methanol, and deionized water in an ultrasonic machine. Finally, it was dried again with an air gun.

Figure 1 shows the fabrication flow diagram of the AAO template. After cleaning the substrate, an aluminum film was deposited on the p-type heavily doped silicon substrate via a thermal evaporator or by sputter deposition. After that, the substrate was annealed in a $400{ }^{\circ} \mathrm{C}$ furnace for $3 \mathrm{~h}$. It was then soaked in oxalic acid for about $30 \mathrm{~min}$ to induce anodization. Then, it was immersed in phosphate for $35 \mathrm{~min}$ at $30{ }^{\circ} \mathrm{C}$ for pore etching. As shown in the scanning electron microscopy (SEM) image in Fig. 2(a), the diameter of each hole was about $79.4 \mathrm{~nm}$. Figure 2(b) shows that the thickness of the aluminum film was about $1.25 \mu \mathrm{m}$. The appearance of the film made from AAO in Fig. 2 was not as good as that of the film made from pure 


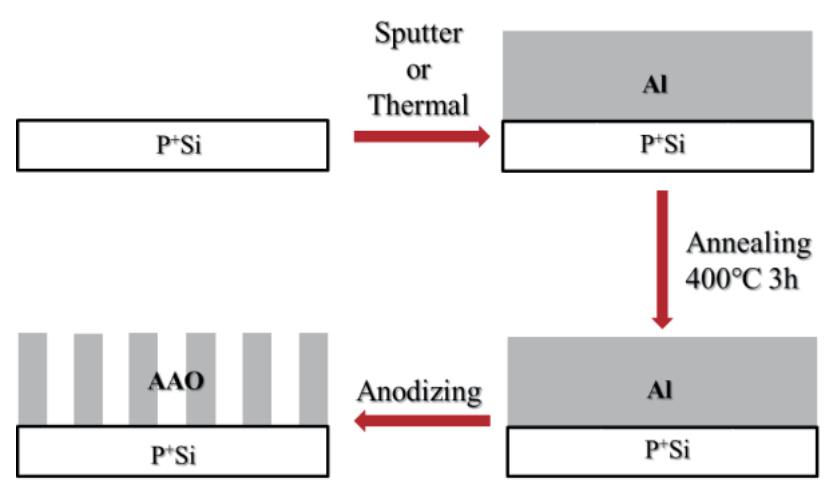

Fig. 1. (Color online) Fabrication flow diagram of AAO template.

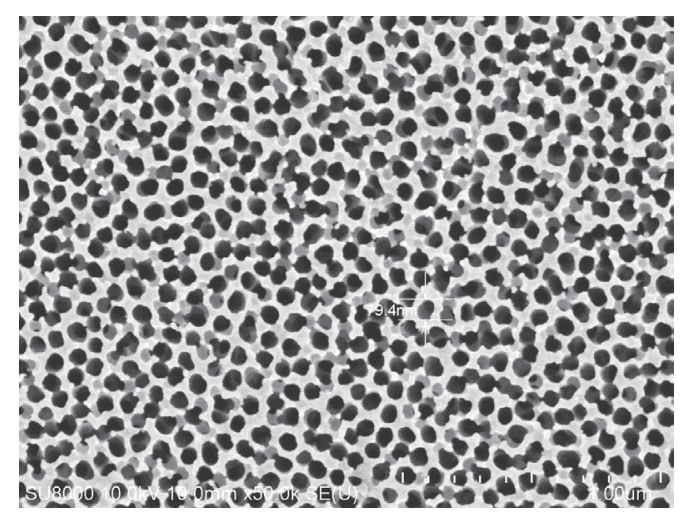

(a)

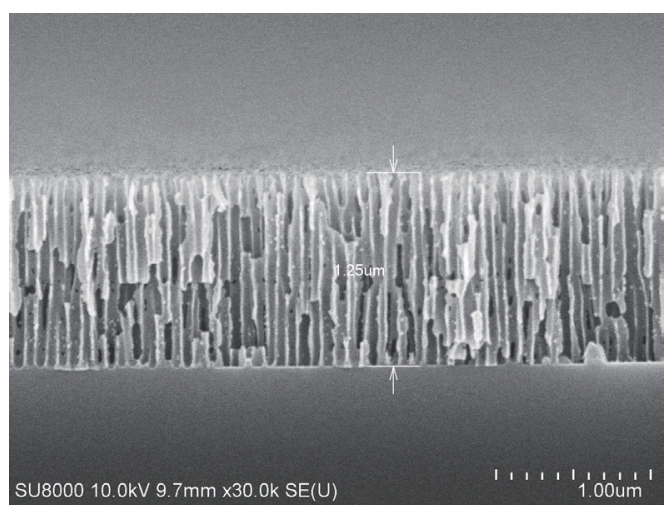

(b)

Fig. 2. SEM images of laboratory-made AAO template: (a) top view and (b) cross section.

aluminum because different fabrication methods were used for the aluminum film AAO and the pure aluminum AAO. However, the hardness and fabrication time of the aluminum film AAO were much greater and shorter than those of the pure aluminum AAO, respectively.

\subsection{Fabrication of $\mathrm{Ni}-\mathrm{Au}$ alloy nanowires}

$\mathrm{Ni}-\mathrm{Au}$ alloy nanowires were deposited in a three-electrode deposition system. The electrolyte for $\mathrm{Ni}-\mathrm{Au}$ electrodeposition was composed of $2.94 \mathrm{mM} \mathrm{HAuCl}_{4} \cdot 4 \mathrm{H}_{2} \mathrm{O}, 2.3 \mathrm{M}$ $\mathrm{NiCl}_{2} \cdot 6 \mathrm{H}_{2} \mathrm{O}, 0.604 \mathrm{M} \mathrm{H}_{3} \mathrm{BO}_{3}$, and $3.75 \mathrm{M}$ DMSO. A saturated calomel electrode was used as a reference electrode, while Pt was used as a counter electrode. Figure 3 shows the fabrication flow diagram of $\mathrm{Ni}-\mathrm{Au}$ alloy nanowires. Before the deposition, the AAO samples were immersed in DMSO solution for at least 30 min to ensure surface polarity. The $\mathrm{Ni}-\mathrm{Au}$ alloy nanowires were formed by alternate pulse deposition at $-1.6 \mathrm{~V}$ for $1300 \mathrm{~s}$ with a duty cycle of $10 \%\left[T_{\text {on }}=1(\mathrm{~s}), T_{\text {off }}=9(\mathrm{~s})\right]$. After deposition, the samples were soaked in $2 \mathrm{M} \mathrm{NaOH}$ in $30{ }^{\circ} \mathrm{C}$ for $1 \mathrm{~h}$ to remove AAO. As shown in Fig. 4(a), holes were completely filled with $\mathrm{Ni}-\mathrm{Au}$ alloy nanowires. Figure 4(b) shows that the Ni-Au alloy nanowires had a uniform arrangement with an average height of $750 \mathrm{~nm}$. 


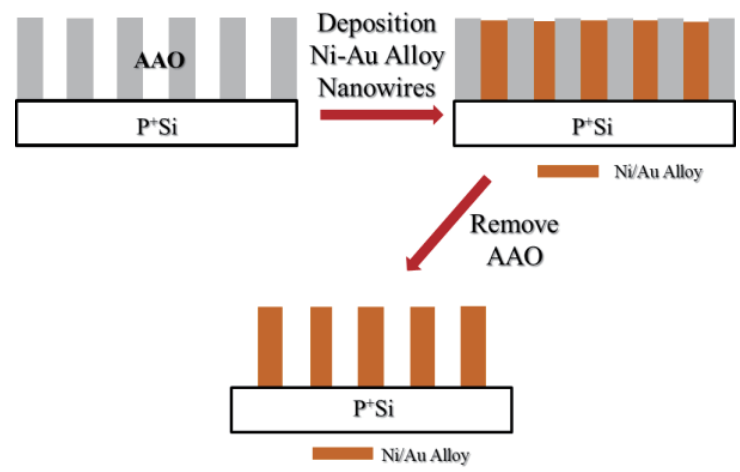

Fig. 3. (Color online) Fabrication flow diagram of $\mathrm{Ni}-\mathrm{Au}$ alloy nanowires.

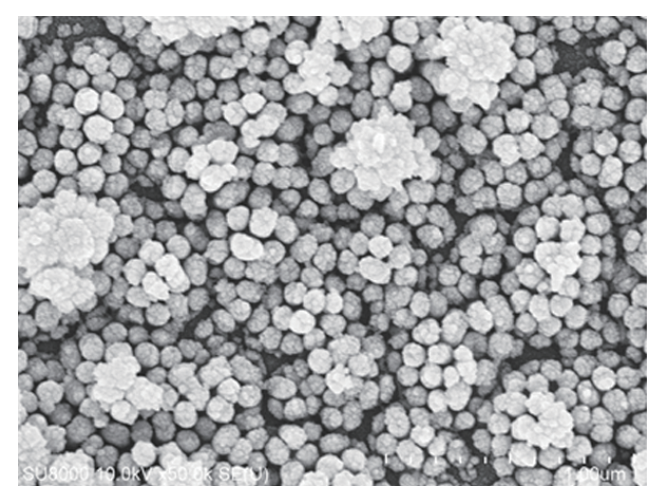

(a)

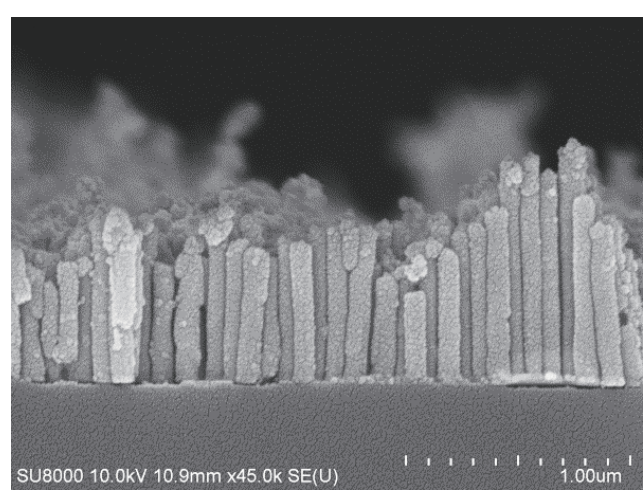

(b)

Fig. 4. SEM images of Ni-Au nanowires: (a) top view and (b) cross section.

Table 1

Element ratio of $\mathrm{Ni}$ and $\mathrm{Au}$ in $\mathrm{Ni}-\mathrm{Au}$ alloy nanowires.

\begin{tabular}{lcc}
\hline Element & Atomic number & Element ratio (\%) \\
\hline $\mathrm{Ni}$ & 28 & 48.74 \\
$\mathrm{Au}$ & 79 & 51.26
\end{tabular}

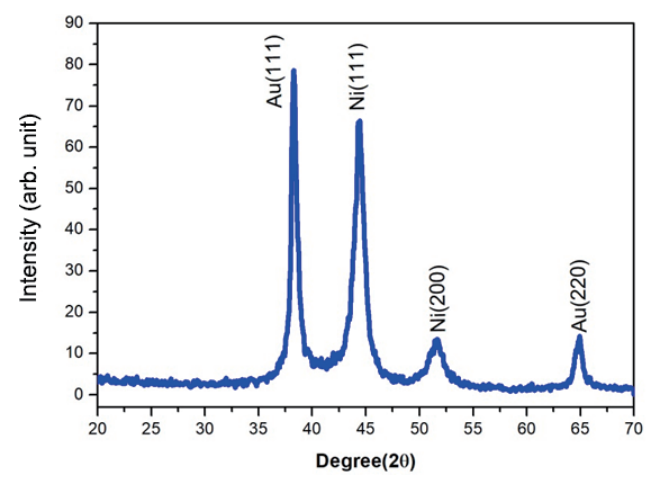

Fig. 5. (Color online) XRD spectrum of $\mathrm{Ni}-\mathrm{Au}$ alloy nanowires.

Energy-dispersive spectrometry (EDS) was used to further analyze the element composition of the nanowires. As shown in Table 1, the nanowires consisted of about 50\% Au and 50\% Ni.

Figure 5 shows the XRD spectrum of the $\mathrm{Ni}-\mathrm{Au}$ alloy nanowires. The two main peaks correspond to $\mathrm{Au}$ (111) and Ni (111) (JCPDS 04-0784 and 04-0850, respectively), proving that the nanowires mainly comprised $\mathrm{Au}$ and $\mathrm{Ni}$. 


\section{Results and Discussion}

\subsection{Cyclic voltammograms and amperometric response}

A $0.1 \mathrm{M} \mathrm{NaOH}$ solution was used to measure glucose owing to its strong oxidation characteristic. During the oxidation of the $\mathrm{Ni}-\mathrm{Au}$ alloy nanowires in the electrode, $\mathrm{CV}$ was performed to accurately obtain the oxidation voltage. The reactions between the $\mathrm{Ni}-\mathrm{Au}$ alloy nanowires, $\mathrm{NaOH}$, and glucose can be expressed by Eqs. (1)-(5). ${ }^{(8-10)}$ When $\mathrm{Ni}$ and Au react with a hydroxyl ion, they become $\mathrm{NiO}(\mathrm{OH})$ and $\mathrm{AuOH}$, respectively, and release an electron. Glucose plays an important role in this reaction because it can convert $\mathrm{NiO}(\mathrm{OH})$ and $\mathrm{AuOH}$ back to $\mathrm{Ni}$ and $\mathrm{Au}$. Through this loop, electrons continue to be released. Therefore, the current becomes larger than that in the absence of glucose.

$$
\begin{gathered}
\mathrm{Ni}+2 \mathrm{OH}^{-} \rightarrow \mathrm{Ni}(\mathrm{OH})_{2} \\
\mathrm{Ni}(\mathrm{OH})_{2}+\mathrm{OH}^{-} \rightarrow \mathrm{NiO}(\mathrm{OH})+\mathrm{H}_{2} \mathrm{O}+\mathrm{e}^{-} \\
\mathrm{NiO}(\mathrm{OH})+\text { glucose } \rightarrow \mathrm{Ni}(\mathrm{OH})_{2}+\text { glucolactone } \\
\mathrm{Au}+\mathrm{OH}^{-} \rightarrow \mathrm{AuOH}+\mathrm{e}^{-} \\
\mathrm{AuOH}+\text { glucose } \rightarrow \mathrm{Au}+\text { glucolactone }
\end{gathered}
$$

The cyclic voltammogram of the $\mathrm{Ni}-\mathrm{Au}$ alloy nanowires in $0.1 \mathrm{M} \mathrm{NaOH}$, which is used to obtain the oxidation and reduction voltage of Ni-Au alloy in Fig. 6(a), has two peaks. The upper curve in this figure shows the anodic peak, which is caused by the oxidation current, and the other curve shows the cathodic peak, which is caused by the reduction current. The redox reaction and CV can be expressed by Eqs. (2) and (4), respectively. The oxidation peak is at $0.4-0.7 \mathrm{~V}$ (vs SCE) and the reduction peak is at $0.15 \mathrm{~V}$ (vs SCE). The scan rate of CV was $0.01 \mathrm{~V} / \mathrm{s}$; a too high scan rate would not have clearly revealed the oxidation peak.

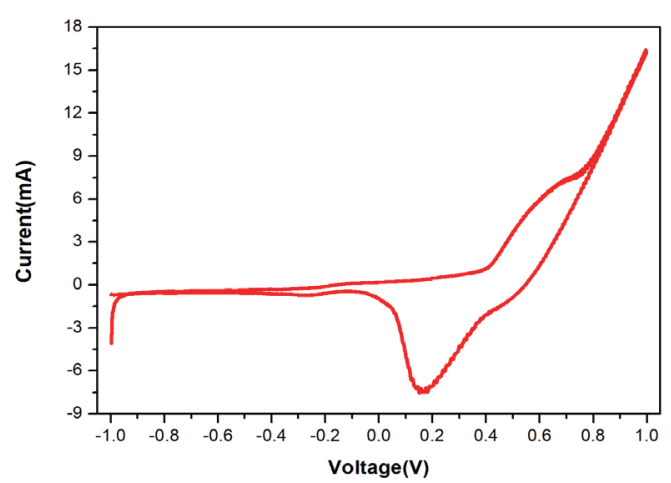

(a)

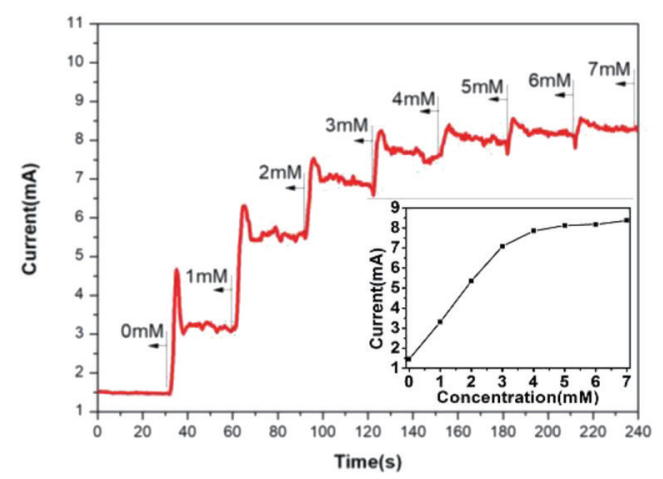

(b)

Fig. 6. (Color online) (a) Cyclic voltammogram from -1 to $1 \mathrm{~V}$ of $\mathrm{Ni}-\mathrm{Au}$ alloy nanowire electrode in $0.1 \mathrm{M}$ $\mathrm{NaOH}$. (b) Amperometric response of $\mathrm{Ni}-\mathrm{Au}$ alloy nanowire electrode to addition of $0.6 \mathrm{ml}$ of $1 \mathrm{M}$ glucose in $0.1 \mathrm{M}$ $\mathrm{NaOH}$ at $0.6 \mathrm{~V}$ (vs SCE). Inset: current versus concentration. 
Figure 6(b) shows the amperometric response at a constant voltage of $0.6 \mathrm{~V}$ (vs SCE) in $0.1 \mathrm{M} \mathrm{NaOH}$. Glucose solution was added every $30 \mathrm{~s}$. Stirring was carried out during the experiment to ensure that the glucose solution was detected evenly. Owing to the fast reaction, the current decreased rapidly as shown in Fig. 6(b). To accurately record the current, the peak current before adding the glucose solution was used as an index to obtain the current versus concentration curve.

\subsection{Sensitivity, linear range, selectivity, stability, and detection limit}

The inset of Fig. 6(b) shows the current versus concentration curve. The relationship is linear in the range of $0-3 \mathrm{mM}\left(R^{2}=0.99858\right)$. The sensitivity of the electrode can be calculated via

$$
\text { Sensitivity }\left(\mu \mathrm{A} / \mathrm{mMcm}^{2}\right)=\frac{\operatorname{Current}(\mu \mathrm{A})}{\text { Concentration }(\mathrm{mM}) \times \operatorname{Area}\left(\mathrm{cm}^{2}\right)} \text {. }
$$

Setting the area of the $\mathrm{Ni}-\mathrm{Au}$ alloy nanowires in Eq. (6) to $1 \mathrm{~cm}^{2}$, we obtained a sensitivity of $1893 \mu \mathrm{A} / \mathrm{mMcm}^{2}$ for the electrode in the range of $0-3 \mathrm{mM}$.

The main application of this non-enzymatic glucose sensor is expected to be measuring blood sugar. However, other substances are present in blood. To ensure that other substances do not affect glucose sensing, we carried out a selectivity test. To simulate a similar environment to the human body, glucose, AA, urea, and UA were used to examine the selectivity of the sensor. Figure 7 shows the amperometric response of the $\mathrm{Ni}-\mathrm{Au}$ alloy nanowires. It is clear that current is only generated with the addition of glucose. In other words, the proposed $\mathrm{Ni}-\mathrm{Au}$ alloy nanowire electrode has excellent selectivity to glucose.

To obtain accurate measurement values, measurements were carried out to determine the detection limit. As shown in Fig. 8, the addition of 10, 50, and $100 \mu \mathrm{m}$ glucose can be detected

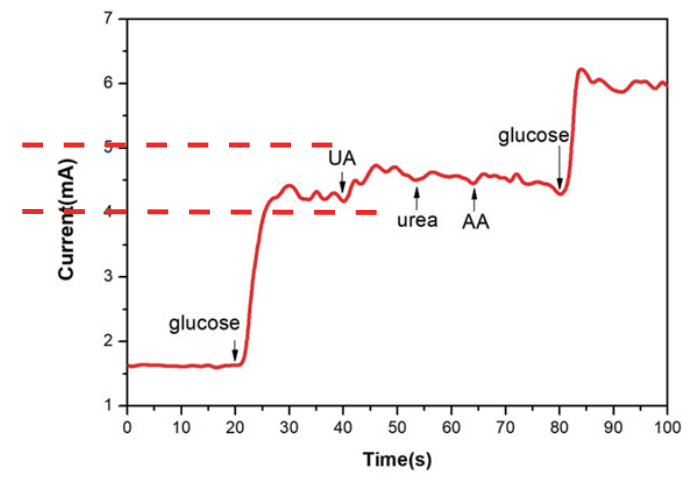

Fig. 7. (Color online) Amperometric response of $\mathrm{Ni}-\mathrm{Au}$ alloy.

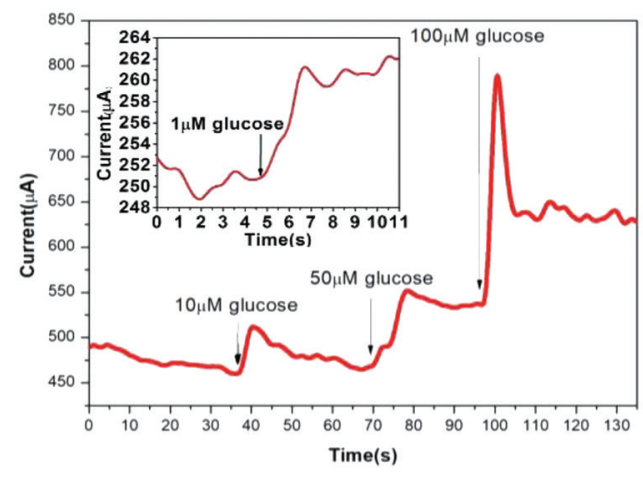

Fig. 8. (Color online) Amperometric response of $\mathrm{Ni}-\mathrm{Au}$ alloy nanowire electrode to addition of small amounts of glucose solution. Inset: amperometric response of $\mathrm{Ni}-\mathrm{Au}$ alloy nanowire electrode to addition of $1 \mu \mathrm{m}$ of glucose solution, UA, urea, and AA. 
Table 2

Comparison of proposed sensor with other non-enzymatic sensors.

\begin{tabular}{lcccccc}
\hline Electrode material & $\begin{array}{c}\text { Sensitivity } \\
\left(\mu \mathrm{AmM}^{-1} \mathrm{~cm}^{-2}\right)\end{array}$ & $\begin{array}{c}\text { Linear range } \\
(\mathrm{mM})\end{array}$ & $\begin{array}{c}\text { Selectivity } \\
(\mathrm{Y} / \mathrm{N})\end{array}$ & $\begin{array}{c}\text { Detection } \\
\text { limit }(\mu \mathrm{M})\end{array}$ & $\begin{array}{c}\text { Stability } \\
(\text { days })\end{array}$ & Reference \\
\hline Ni nanowires & 1043 & $0.0005-7$ & $\mathrm{Y}$ & 0.1 & 65 & 8 \\
Au nanowires & 309 & $0-10$ & $\mathrm{Y}$ & 50 & 60 & 9 \\
CNT-Ni nanostructures & 1300 & $0.5-10$ & $\mathrm{Y}$ & 1 & 15 & 16 \\
PtNi alloy nanoparticles & 1795.1 & $0.002-0.42$ & $\mathrm{Y}$ & 1 & $\mathrm{~N} / \mathrm{A}$ & 17 \\
$\mathrm{Ni}(\mathrm{OH})_{2}-\mathrm{Au}$ nanohybrid & 371.2 & $0.005-2.2$ & $\mathrm{Y}$ & 0.92 & At least 21 & 18 \\
$\mathrm{Ni}-\mathrm{Ag}$ carbon nanotubes & 2946 & $0-0.35$ & $\mathrm{Y}$ & 0.062 & At least 22 & 19 \\
$\mathrm{Au}$ nanoparticles & 160 & $0.5-8$ & $\mathrm{Y}$ & 0.5 & N/A & 20 \\
$\mathrm{Au}-\mathrm{Ni}$ multilayer nanowires & 3372 & $0.00025-2.2$ & $\mathrm{Y}$ & 0.1 & At least 21 & 10 \\
Ni-Au alloy nanowires & 1893 & $0.001-3$ & $\mathrm{Y}$ & 1 & At least 30 This work \\
\hline
\end{tabular}

by the $\mathrm{Ni}-\mathrm{Au}$ alloy nanowire electrode. The inset shows that the addition of $1 \mu \mathrm{m}$ glucose can also be detected. Therefore, the detection limit of the Ni-Au alloy nanowires is $1 \mu \mathrm{m}$. The stability of the electrode was also evaluated. After 30 days of measurement, the sensitivity was $95 \%$ of its original value, demonstrating the high stability of the $\mathrm{Ni}-\mathrm{Au}$ alloy nanowire electrode.

Table 2 shows a comparison of the proposed sensor with other previously reported nonenzymatic sensors. Compared with the other sensors, the $\mathrm{Ni}-\mathrm{Au}$ alloy nanowire electrode has a very high sensitivity, a wide linear range, a low detection limit, and a high stability.

\section{Conclusion}

$\mathrm{Ni}-\mathrm{Au}$ alloy nanowires were fabricated using a laboratory-made AAO template fabricated on a p-type heavily doped silicon substrate. Despite the considerably different reduction voltages of $\mathrm{Ni}$ and $\mathrm{Au}$, we successfully fabricated the $\mathrm{Ni}-\mathrm{Au}$ alloy nanowires by adjusting the electrodeposition parameter. A sensor using $\mathrm{Ni}-\mathrm{Au}$ alloy nanowires as the electrode exhibited excellent sensitivity, a wide linear range, a low detection limit, and a high stability, making it ideal for use as a non-enzymatic glucose sensor.

\section{Acknowledgments}

This work was supported by the Ministry of Science and Technology (MOST) of Taiwan under Contract Nos. MOST 107-2221-E-006-159 and MOST 108-2221-E-230-006.

\section{References}

1 L. Heinemann and G. Schmelzeisen-Redeker: Diabetologia 41 (1998) 848. https://link.springer.com/ article $/ 10.1007 \% 2 \mathrm{Fs} 001250050998$ ? LI $=$ true

2 J. B. Slate and P. C. Lord: U.S. Patent No. 5605152 (25 Feb. 1997). https://patents.google.com/patent/ US5605152A/en

3 S. Mansouri and J. S. Schultz: Bio/Technology 2 (1984) 885. https://www.nature.com/articles/nbt1084-885

4 R. Wilson and A. P. F. Turner: Biosens. Bioelectron. 7 (1992) 165. https://www.sciencedirect.com/science/ article/pii/095656639287013F 
5 S. Changsheng, Y. Huafeng, S. Jiangfeng, H. Dongxue, A. Ivaska, and L. Niu: Anal. Chem. 81 (2009) 2378. https://pubs.acs.org/doi/abs/10.1021/ac802193c

6 L. Jing, J. Sisi, Z. Hongyan, J. Jinqiang, and L. XiaoyaLiu: Anal. Chim. Acta 709 (2012) 47. https://www. sciencedirect.com/science/article/pii/S0003267011013754

7 S. Park, H. Boo, and C. T. Dong: Anal. Chim. Acta 556 (2006) 46. https://www.sciencedirect.com/science/ article/pii/S0003267005009864

8 L. Li-Min, Z. Li, Q. Feng-Li, L. Hai-Xia, Z. Xiao-Bing, W. Zai-Sheng, H. Shuang-Yan, W. Qiu-An, S. Guo-Li, and Y. Ru-Qin: Biosens. Bioelectron. 25 (2009) 218. https://www.sciencedirect.com/science/article/pii/ S0925400509005784

9 Q. Lirong, H. Lizhong, Z. Jianwei, Z. Binglin, Y. Yingying, and Y. Yu: Sens. Actuators, B 240 (2017) 779. https://www.sciencedirect.com/science/article/pii/S0925400516314599

10 S. Cherevko and C.-H. Chung: Sens. Actuators, B 142 (2009) 216. https://www.sciencedirect.com/science/ article/pii/S0925400509005784

11 C. Zhengbo, G. Junxia, Z. Tong, Z. Youwei, and C. Liang: Electrochim. Acta 109 (2013) 532. https://www. sciencedirect.com/science/article/pii/S0013468613015314

12 G. Zhi-Da, H. Yuyao, W, Yongmei, X. Jingwen, and S. Yan-Yan: Sci. Rep. 3 (2013) 3323. https://www.nature. com/articles/srep03323

13 C. Li, H. Wang, and Y. Yamauchi: Chem. Eur. J. 19 (2013) 2242. https://onlinelibrary.wiley.com/doi/ full/10.1002/chem. 201203378

14 C. Hui-Fang, Y. Jian-Shan, L. Xiao, Z. Wei-De, and S. Fwu-Shan: Nanotechnol. 17 (2006) 2334. https:// iopscience.iop.org/article/10.1088/0957-4484/17/9/043/meta

15 N. Hui-Bog, L. Kyung-Sun, C. Pranjal, W. Mi-Sook, and S. Yoon-Bo.: Electrochim. Acta 61 (2012) 36. https:// www.sciencedirect.com/science/article/pii/S0013468611017397

16 Z. Jianhui, J. Jian, L. Jinping, D. Ruimin, L. Yuanyuan, D. Hao, F. Yamin, W. Guangming, and H. Xintang : RSC Adv. 1 (2011) 1020. https://pubs.rsc.org/en/Content/ArticleLanding/2011/RA/c1ra00280e\#!divAbstract

17 S. Qu, M. He, W. Huimin, Z. Xiuhua, and W. Shengfu: Sens. Actuators, B 203 (2014) 588. https://www. sciencedirect.com/science/article/pii/S0925400514007795

18 J. Chen and J. Zheng: J. Electroanal. Chem. 749 (2015) 83. https://www.sciencedirect.com/science/article/pii/ S1572665715002192

19 L. Weiwei, O. Ruizhuo, Z. Wangyao, Z. Shuang, Y. Yang, J. Yajun, Y. Yang, F. Kai, L. Xiaocai, X. Mingshu, and M. Yuqing: Electrochim. Acta 188 (2016) 197. https://www.sciencedirect.com/science/article/pii/ S0013468615309269

20 F. Kurniawan, V. Tsakova, and V. M. Mirsky: Electroanalysis 18 (2006) 1937. https://onlinelibrary.wiley.com/ doi/abs/10.1002/elan.200603607 